\title{
Existe uma Bolha Imobiliária no Brasil? Uma Análise Teórica e Empírica
}

\section{Is there a Housing Bubble in Brazil? A Theoretical and Empirical Analysis}

\author{
Assilio Araujo* \\ Fernando Ferrari Filho** \\ Eduardo Bueno*** \\ "What you can't understand (...) For the times they are a changing." \\ (Bob Dylan, Times they are a changing, 1964)
}

\begin{abstract}
Resumo: Tendo como referência o approach teórico pós-keynesiano, o objetivo do presente artigo consiste em verificar se existe uma bolha imobiliária no Brasil. Para tanto, em um primeiro momento, analisa-se o comportamento de alguns indicadores, que, de acordo com a referida teoria, poderiam sugerir a existência de uma bolha especulativa no mercado imobiliário. Posteriormente, realizam-se alguns procedimentos econométricos a fim de se constatar em que medida o aumento do preço dos imóveis no Brasil está relacionado à alteração de algumas variáveis fundamentais ou à possibilidade de comportamento especulativo por parte dos agentes econômicos no mercado imobiliário. Este estudo apresenta duas conclusões: por um lado, os resultados mostram que os custos de produção e outras variáveis fundamentais não são suficientes para explicar o aumento significativo dos preços dos imóveis no Brasil nos últimos anos; e, por outro lado, o comportamento do crédito, a postura financeira das famílias e as condições gerais da economia corroboram a hipótese da existência de uma bolha no mercado imobiliário.
\end{abstract}

Palavras-chave: Bolha imobiliária. Teoria pós-keynesiana. Análise empírica.

\begin{abstract}
Based on the post-Keynesian theory, the article aims at verifying if there is a housing bubble in Brazil. First, we analyze the behavior of some specific indicators that, according to this theory, could show the existence of a housing bubble in the real estate. Secondly, econometric techniques are used to estimate an economic model to show the relationship between the housing price and changes in the fundamental variables or the possibility of speculative behavior of economic agents in the real estate. The article

* $\quad$ Mestre em Economia pelo Programa de Pós-Graduação em Economia (PPGE) da Universidade Federal do Rio Grande do Sul (UFRGS). Assessor econômico do Sinduscon-RS. E-mail: assilioaraujo@hotmail.com

* * Doutor em Economia pela Universidade de São Paulo (USP). Professor titular do Departamento de Economia e Relações Internacionais (DERI) da Universidade Federal do Rio Grande do Sul (UFRGS). Pesquisador do CNPq. E-mail: ferrari@ufrgs.br

*** $\quad$ Mestre em Economia pelo Programa de Pós-Graduação em Economia (PPGE) da Universidade Federal do Rio Grande do Sul (UFRGS). Servidor público federal. E-mail: eduardo.u.bueno@ gmail.com
\end{abstract}


presents two main conclusions: on the one hand, our results show that the production costs and some fundamental variables are not enough to explain, in the last years, the housing prices in the Brazilian real estate; and, on the other hand, however it is possible to argue that credit behavior, financial position of households and general economic conditions corroborate to the existence of a housing bubble in the real estate.

Keywords: Housing bubble. Post-Keynesian theory. Empirical analysis.

JEL Classification: E30.

\section{Introdução}

Com a crise do subprime nos Estados Unidos (2007-2008), cujas consequências foram a crise financeira mundial e a Grande Recessão, as especulações e análises sobre bolhas imobiliárias, seja em países desenvolvidos, seja em países emergentes, tornaram-se recorrentes.

No Brasil, não foi diferente. O aumento exponencial dos preços dos imóveis nos últimos anos, notadamente nos principais centros urbanos (Rio de Janeiro e São Paulo), suscitou uma série de considerações a respeito da possibilidade de existir uma bolha imobiliária no país.

Nesse particular, uma das declarações de maior impacto foi a do Prêmio Nobel de Economia, Robert Shiller, ao comentar os preços no mercado imobiliário brasileiro, quando de sua visita ao Brasil em outubro de 2013. Segundo ele, "[...] algo não está correto nisso. O que pode ter acontecido para justificar uma variação tão grande de preços? [...] Não tenho prova objetiva de que há uma bolha aqui, mas existe indicação de que algo acontece" (O GLOBO, 2013, on line).

Nouriel Roubini, por sua vez, em um artigo publicado no site Project Syndicate, em 29 de novembro de 2013, escreveu que

Now, five years later, signs of frothiness, if not outright bubbles, are rea-
ppearing in housing markets in Switzerland, Sweden, Norway, Finland,
France, Germany, Canada, Australia, New Zealand, and, back for an en-
core, the UK (well, London). In emerging markets, bubbles are appearing
in Hong Kong, Singapore, China, and Israel, and in major urban centers
in Turkey, India, Indonesia, and Brazil (ROUBINI, 2013, on-line).

Em 2014, o Bank for International Settlements (BIS) também emitiu uma opinião nesse sentido em uma análise feita em seu relatório anual sobre a situação da economia mundial e os riscos envolvidos na manutenção, por um tempo excessivo, da política monetária acomodatícia nos países centrais. Quanto à situação dos países emergentes, dentre os quais o Brasil foi mencionado, a análise do BIS era a de que "[...] measures of credit expansion and the speed of property price inflation, which have been reliable early warning indicators, are flashing red lights about a 
number of emerging market economies at the current juncture." (BANK FOR INTERNATIONAL SETTLEMENTS, 2014, p. 120).

Além dessas considerações, alguns artigos corroboram a ideia da existência de uma bolha imobiliária no Brasil (D'AGOSTINI, 2010; LIMA JÚNIOR, 2011; MENDONÇA; SACHSIDA, 2012). ${ }^{1}$

Diante desse contexto, o objetivo do presente trabalho consiste em verificar se existe uma bolha imobiliária no Brasil. Para tanto, o artigo está dividido em três seções, além desta introdução. Na segunda seção, tendo como referência a teoria pós-keynesiana, se define e se apresenta como é observada uma bolha de ativo sem economias monetárias de produção, visando, com isso, analisar o caso específico de bolha no mercado imobiliário. Em seguida, na terceira seção, é realizada uma análise empírica do caso brasileiro, seja por meio da investigação de uma série de indicadores dos mercados imobiliários e de crédito, seja através de procedimentos econométricos. Por fim, tendo como base indícios de que há um comportamento especulativo no mercado imobiliário brasileiro, na quarta seção se especula sobre possíveis desdobramentos e impactos de uma deflação dos preços no referido mercado.

\section{Bolhas de Ativos: uma Análise Pós-Keynesiana}

O ponto de partida para se discutir sobre bolha de ativos na análise pós-keynesiana é a compreensão da dinâmica de uma economia monetária, conforme desenvolvida por Keynes em The general theory of employment, interest and money (de agora em diante, GT). Segundo Keynes (2007, p. VII), "[...] [a] monetary economy [...] is essentially one in which changing views about the future are capable of influencing the quantity of employment and not merely its direction".

Pelo menos, dois capítulos da GT, 12 e 17, são fundamentais para se entender a relação entre incerteza, moeda e desemprego, essência do funcionamento de economias monetárias.

No capítulo 12, Keynes apresenta uma concepção metodológica fundamental da GT, qual seja, a incerteza. No referido capítulo, ao analisar quais são os fatores que condicionam as expectativas sobre a renda esperada de um bem de capital, a ideia consiste em mostrar que as expectativas são formadas em um contexto de incerteza fundamental. Mas o que é incerteza? Para Keynes, incerteza significa que o estado de opinião é relativo para determinado grau de conhecimento limitado. Conforme Keynes, "[...] 'very uncertain' [...] [does] not mean the same thing as 'very improbable' [...]” (KEYNES, 2007, p. 148). Mais adiante, ele afirma que

1 Outros trabalhos exploram essa mesma questão para regiões específicas do Brasil. Marçal et al. (2012) e Carvalho (2012) avaliam o caso de São Paulo, enquanto Bezerra et al. (2013) tratam do caso de Natal. 
"[...] human decisions affecting the future, whether personal or political or economic, cannot depend on strict mathematical expectation, since the basis for making such calculations does not exist [...]" (KEYNES, 2007, p.162-163). Ademais, em The general theory and after Keynes deixa clara a distinção entre incerteza e risco probabilístico: “[...] 'uncertain' knowledge [...] I do not mean merely to distinguish what is known for certain from what is only probable [...] The sense in which I am using the term is that [...] there is no scientific basis on which to form any calculable probability whatever. We simply do not know" (KEYNES, 1973, p. 113-114).

Segundo Dymski (2004, p. 405), "[...] o futuro é incerto porque os acontecimentos que se desenrolam em tempo real não obedecem a distribuição de probabilidade predeterminadas [...]". Portanto, as tomadas de decisões são afetadas à luz de um passado inalterado movendo-se para um futuro desconhecido.

No capítulo 17 da GT, Keynes elabora uma teoria de precificação dos ativos objetivando mostrar como as decisões de gastos, consumo e investimento são influenciadas pela preferência pela liquidez (PL). Em outras palavras, Keynes mostra como a taxa de juros, em termos monetários, exerce um papel peculiar na limitação do nível de emprego, uma vez que influencia a propensão marginal a consumir (PMgC) e a eficiência marginal do capital (EMgC).

Para compreender a relação entre PL, PMgC e EMgC, Dymski (2004) chama a atenção para outro conceito metodológico relevante na teoria de Keynes, qual seja, o tempo real. Segundo Dymski, "[...] [o] tempo real [...] significa que os agentes que procuram acumular riqueza têm de adquirir e reter ativos parcial ou totalmente ilíquidos durante uma série de curtos períodos, ao longo dos quais é possível que as condições de mercado mudem substancialmente." (DYMSKI, 2004, p. 405).

A ideia de tempo real nos leva à diferença entre os preços/contratos spot e forward: no spot market, as transações (pagamentos e entregas de bens e serviços) entre compradores e vendedores são realizadas imediatamente, ao passo que, no forward market, os compradores e vendedores têm um contrato que diz que as transações (pagamentos e entregas de bens e serviços) serão realizadas em uma data futura. Nesse particular, segundo Davidson (1994), a existência de contratos em moeda permite a repartição das cargas de incertezas entre as partes contratantes para, em um futuro, liquidar obrigações, executar compromissos, etc. Ademais, se os contratos não forem do tipo spot, mas, sim, forward, a taxa monetária de juros deve ser levada em consideração para a realização deles.

Considerando essas definições de incerteza, de tempo real e de preços/contratos spot e forward, Keynes mostra que o preço (ou taxa de juros) de um ativo (PA) é composto pelos seguintes elementos: valor de mercado do ativo (a), rendimento esperado do ativo $(q)$, custo de conservação do ativo $(c)$ e prêmio de liquidez do ativo ( $l$ ). Assim, em geral, o preço do ativo é formado por: 


$$
\mathrm{PA}=a+q-c+l(1)
$$

Dessa maneira, cada ativo tem seu preço (taxa de juros) definido em termos de preços correntes, no qual a PL - taxa de juros que representa a recompensa por se abrir mão de liquidez na retenção de moeda - é expressa em termos do trade-off entre o retorno monetário $(a+q-c)$ e o prêmio de liquidez da moeda $(l)$.

Davidson (1994, p. 114) argumenta que "[...] since the spot market price of liquid assets can change over time, savers must contemplate the possibility of an appreciation or depreciation in the assets's market price at a future data when the holder wishes to liquidate his or her holdings [...]".

Assim, se reescreve a equação 1 de maneira a incorporar os possíveis ganhos (ou perdas) de capital decorrentes da "[...] subtracting today's spot price $\left(\mathrm{p}_{\mathrm{s}}^{{ }^{0}}\right)$ from the expected spot price at a future date $\left(\mathrm{p}_{\mathrm{s}}^{\mathrm{t}}\right)$ when the asset will be resold [...]" (DAVIDSON, 1994, p. 114).

Nesse sentido, dependendo das posições bulls ou bears ${ }^{2}$ dos agentes, são estabelecidas as seguintes relações:

$$
(q-c)+\left(p_{s}^{t 1}-p_{s}^{t 0}\right)-T>0
$$

e

$$
(q-c)+\left(p_{s}^{t 1}-p_{s}^{t 0}\right)-T<0
$$

em que $T$ é o custo de transação.

Na equação 2, o agente é bull e "[...] will buy all the asset that he or she currently can afford" (DAVIDSON, 1994, p. 115), enquanto que, conforme a equação 3, ele é um agente bear que "[...] would prefer to hold money rather than the liquid asset for these speculative purposes" (DAVIDSON, 1994, p. 115). Em suma, quando a incerteza é fundamental, a demanda por um ativo líquido cresce.

A questão torna-se mais complexa pelo fato de que, conforme Dymski (2004, p. 405), “[...] não há como saber 'objetivamente' se os preços dos ativos sobem porque os fundamentos estão melhorando ou porque estão sendo avaliados de maneira diferente". Assim, a análise de Keynes mostra que os agentes econômicos abrem mão de liquidez em períodos de crescimento econômico e de elevação do valor/preço dos ativos e demandam liquidez quando a economia entra em crise e o valor/preço dos ativos cai.

2 Segundo Keynes (1976, p. 250), "[...] a 'bear' [...] is one who prefers at the moment to avoid securities and lend cash, and correspondingly a 'bull' is one who prefers to hold securities and borrow cash - the former anticipating that securities will fall in cash-value and the latter that they will rise." 
Tendo como referência as ideias e argumentos desenvolvidos, acredita-se que crises de insuficiência de demanda efetiva e, por conseguinte, desemprego ocorrem porque os agentes econômicos, ao desconhecerem quais serão os resultados de seus planos de investimento, consumo e transações em um futuro próximo, passam a demandar moeda, seja por esta representar um elo com relações reais através dos contratos, seja por se constituir na defesa contra a incerteza acerca do futuro.

Partindo dessa análise keynesiana de precificação dos ativos, a abordagem pós-keynesiana consiste em mostrar como os agentes econômicos formam suas expectativas sobre o comportamento futuro dos preços dos ativos.

Nesse particular, Minsky (2008) formaliza um modelo de determinação do investimento, denominado hipótese de fragilidade financeira ( $\mathrm{HFF}$ ), a partir da relação entre os preços de oferta e de demanda do capital e o funding, seja do sistema financeiro, seja de quaisquer "investidores/poupadores" institucionais, para custear o investimento. A ideia é que as firmas e os bancos têm de ter expectativas convergentes para que o financiamento do investimento ocorra.

Analiticamente, o investimento agregado é determinado pela seguinte equação:

$$
\mathrm{PI}=\mathrm{PK}\left(\mathrm{M}, \mathrm{Q}_{\mathrm{i}}\right)
$$

em que $\partial \mathrm{PK} / \partial \mathrm{M}$ e $\partial \mathrm{PK} / \partial \mathrm{Q}>0 ; \mathrm{PI}=$ preço de oferta/custo do bem de capital; $\mathrm{PK}=$ preço de demanda/mercado do bem de capital; $\mathrm{M}$ = quantidade de moeda; $\mathrm{e} \mathrm{Q}=$ rendimento esperado do bem de capital.

É importante ressaltar que, no modelo de Minsky, da mesma forma que as expectativas dos agentes econômicos mudam conforme o ciclo econômico, as relações de balance sheet também sofrem modificações ao longo desse ciclo.

Pela equação 4, conforme Dymski (2004, p. 407), a evolução dos balanços é acompanhada por um "[...] padrão cíclico no relacionamento entre os preços do mercado e os custos de produção dos bens de capital". Assim, se PK > PI, o ciclo de expansão, resultante da combinação de expectativas positivas e alavancagem (elevação da relação dívida/receita), acaba gerando uma bolha de ativos, ao passo que se PK/PI cai, e, adicionalmente, $\mathrm{PK}<\mathrm{PI}$, o que faz com que as obrigações/dívidas cresçam, a economia desacelera e entra em colapso. Em outras palavras, em período de prosperidade, os investimentos se elevam, os empréstimos bancários crescem e há uma inflação de ativos. Por sua vez, em períodos de crise, os investimentos são postergados, há escassez de crédito e, por conseguinte, elevação da taxa de juros, o que acaba diminuindo o valor presente descontado do projeto de investimento, deixando as firmas em posições frágeis, pois seus custos financeiros aumentam. 
Conforme a HFF, a atividade econômica e as relações financeiras que viabilizam o investimento dependem do "grau de confiança" no sistema econômico, envolvendo as expectativas de renda futura dos que assumem dívidas (investidores) e as expectativas de retorno-risco dos que adquirem ativos financeiros (poupadores e instituições financeiras).

Ademais, para Minsky, a estrutura de financiamento do investimento, ou a postura financeira das firmas, pode ocorrer de três formas: a) hedge, que é a situação na qual os lucros correntes das firmas excedem os custos (amortização e juros) de financiamento das dívidas contraídas junto ao sistema financeiro; b) de forma especulativa, em que a postura de risco do fluxo de receita esperada do investimento tende, na média, a igualar o fluxo de pagamento do empréstimo contraído pela firma - durante certo período de tempo, as receitas cobrem apenas as despesas de juros, sendo, assim, necessário refinanciar a amortização; e c) Ponzi, denominada estrutura "suicida", em que o fluxo de receita esperada do investimento é sempre inferior ao fluxo de pagamento do empréstimo contraído pela firma.

Diante desse contexto, surgem duas questões: o que é bolha de ativos na visão pós-keynesiana? Como ela se manifesta? Bolha de ativos reflete comportamentos irracionais dos agentes econômicos no sentido de que os preços no futuro tendem a crescer indefinidamente, independentemente dos fundamentos no presente não justificarem essa tendência. Alternativamente, bolha de ativos se constitui em uma situação na qual a relação entre os preços dos ativos, reais e financeiros, entre outros, e os custos de produção dos bens de capital crescem ao longo do tempo.

Por sua vez, a existência de uma bolha de ativos está relacionada ao contexto de flutuações cíclicas nos níveis de renda e emprego. Em outras palavras, na fase de expansão e prosperidade econômica, o grau de endividamento das firmas se eleva, produzindo, assim, uma deterioração das suas posturas financeiras, que deixam de ser hedge e entram em posturas financeiras especulativas e Ponzi.

Nas palavras de Dymski, ao ressaltar o papel das bolhas de ativos nas flutuações econômicas,

[...] [o] ritmo acelerado de crescimento do produto acaba por exaurir a capacidade industrial e obriga as empresas a contraírem dívidas para aumentar a produção. A combinação de expectativas eufóricas e pressão da concorrência puxa para cima ao mesmo tempo a relação dívida/recita e o preço dos ativos: a alavancagem é recompensada. Quando o colapso chega, ele é muito rápido (DYMSKI, 2004, p. 407-408).

Em suma, segundo a teoria pós-keynesiana, a existência de bolhas de ativos é inerente à dinâmica operacional de economias monetárias, em que um longo período de estabilidade leva a economia, inevitavelmente, à instabilidade, devido ao fato de que as expectativas dos agentes econômicos acerca dos preços futuros 
dos ativos são formadas em bases frágeis - diga-se de passagem, são fragilizadas porque as informações de mercados são heterogêneas e não são completas, entre outras - e dependem, em grande parte, do "estado de confiança". ${ }^{3}$

\section{Análise Empírica Sobre Bolha Imobiliária no Brasil}

\subsection{Análise Descritiva}

Depois de um longo período de quase estagnação, o mercado imobiliário brasileiro apresentou um boom na segunda metade dos anos 2000, impulsionado por uma série de fatores econômicos e institucionais. ${ }^{4} \mathrm{O}$ Gráfico 1 mostra a evolução do índice de valores de garantia de imóveis residenciais financiados (IVG-R), calculado pelo Banco Central do Brasil (BCB), entre janeiro de 2004 e novembro de 2014.

Gráfico 1 - Variação real dos preços dos imóveis no Brasil (\% a.a.) no período 2004-2014

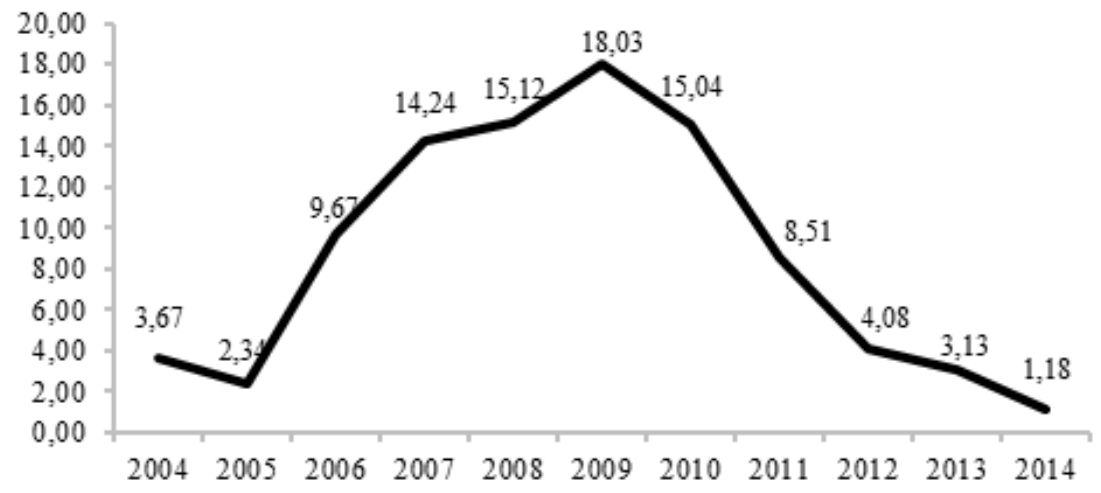

Fonte: Banco Central do Brasil (2015).

Nota: Série deflacionada pelo IPCA; variação acumulada até novembro.

3 Não é demais ressaltar que o "estado de confiança", as convenções e as instituições são fundamentais para balizar o animal spirits do empresário para que ele possa tomar decisões de investimento. Para tanto, ver Ferrari Filho e Conceição (2005).

4 Os fatores econômicos são conhecidos por todos, tratando-se especialmente da expansão do crédito imobiliário, do crescimento do emprego e da renda, da relativa estabilidade de preços conjugada com um maior crescimento econômico e dos programas de investimento do governo federal, notadamente o Programa de Aceleração do Crescimento (PAC) e o Minha Casa, Minha Vida. Do lado institucional, merecem destaque: a) a promulgação da Lei ${ }^{\circ} 10.931 / 2004$, que garantiu maior segurança jurídica para o setor; b) as resoluções do Conselho Monetário Nacional obrigando as instituições financeiras a destinarem parte dos recursos da caderneta de poupança para o financiamento imobiliário; e c) o processo de abertura de capital de uma série de empresas do setor a partir de 2005-2006, que, além de promover um aumento significativo do volume de recursos, gerou uma mudança na estratégia das grandes empresas, no sentido de uma "nacionalização" e da entrada em nichos de mercado antes inexplorados ou subexplorados, como o mercado de habitação popular (CARDOSO; LEAL, 2010). 
Como se pode observar, o referido índice apresentou uma variação real média de $8,64 \%$ ao ano, com um pico de $18,03 \%$ ao ano em 2009. A variação acumulada nesse período foi de $159,75 \%$.

É claro que, assim como em outros países que vivenciaram um comportamento similar no mercado imobiliário, a variação não foi homogênea entre as diversas cidades e regiões. ${ }^{5}$ Algumas, como Rio de Janeiro, São Paulo e Recife, apresentaram um crescimento anual médio dos preços dos imóveis, em termos reais, próximo a 10\%, entre 2011 e 2014, ao passo que outras, como Salvador e Distrito Federal, registraram uma variação relativamente inexpressiva (Salvador), ou até mesmo negativa (Distrito Federal), de acordo com o índice FipeZap de preços de imóveis anunciados (ver Gráfico 2). ${ }^{6}$

Gráfico 2 - Variação anual média dos preços, em termos reais, dos imóveis em algumas cidades selecionadas (\%), no período 2011-2014

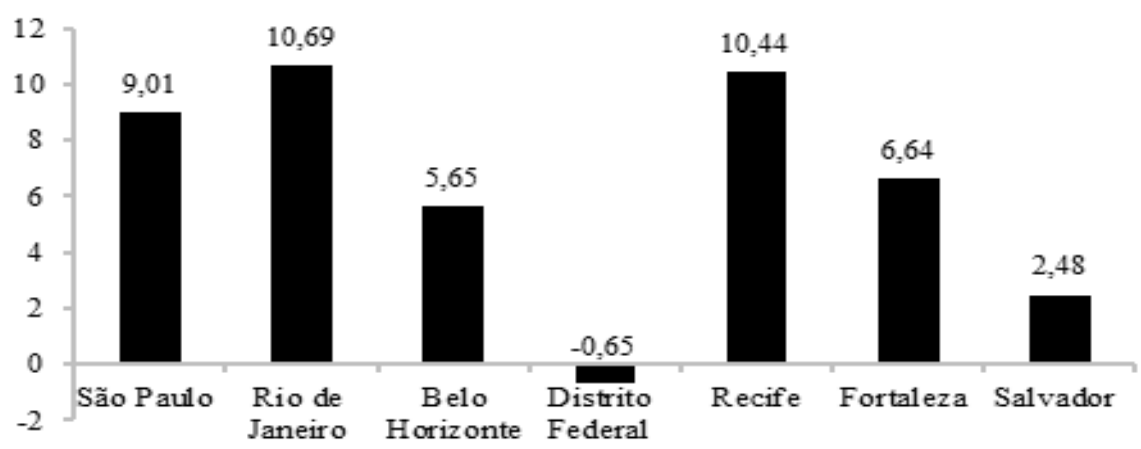

Fonte: Fundação Instituto de Pesquisas Econômicas (2015).

Nota: Série deflacionada pelo IPCA.

Comparando com o índice nacional de custos da construção (INCC), observa-se que o crescimento dos preços dos imóveis foi muito superior ao dos custos de construção. A variação real acumulada dos custos, medida pelo referido índice, foi de $21,72 \%$ entre janeiro de 2004 e novembro de 2014; portanto, muito abaixo da variação real do IVG-R no mesmo período. Logo, o aumento da relação preços dos ativos/custos de produção, apontado na seção teórica como sendo uma das formas pelas quais uma bolha de ativos se manifesta, se observou ao longo do período, como evidenciado no Gráfico 3.

$5 \quad$ Tendo como referência o índice Case-Shiller, Lima Júnior (2014) mostra que nem todas as cidades dos Estados Unidos tiveram uma valorização imobiliária significativa antes da crise do subprime.

6 Nesse caso, foi utilizado o Índice FipeZap, pois o IVG-R é um índice agregado para todo o território nacional, calculado com base nos dados de 11 regiões metropolitanas. O critério para a escolha dessas cidades foi por possuírem uma série histórica um pouco mais longa que as demais (a partir de 2011). 
Gráfico 3 - Relação preços dos imóveis/custos de construção no período de janeiro de 2004 a novembro de 2014

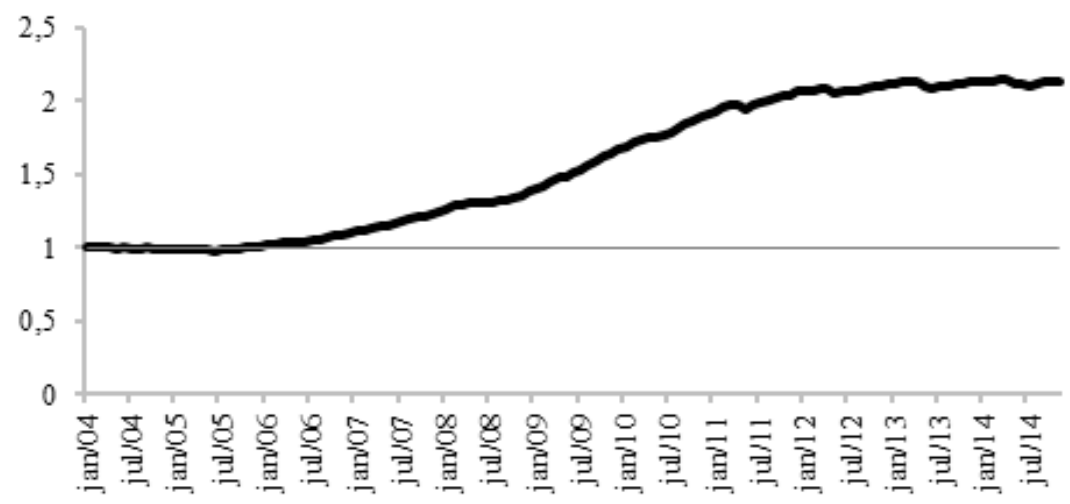

Fonte: Elaboração própria a partir de Banco Central do Brasil (2015) e Câmara Brasileira da Indústria da Construção (2015).

No entanto, deve-se fazer uma ressalva em relação a esse resultado, qual seja, o INCC não capta todos os fatores que constituem o custo global de um empreendimento imobiliário. Os terrenos, por exemplo, que representam parte significativa desses custos e que tiveram uma valorização bastante substancial nos últimos anos, sobretudo nos grandes centros urbanos, não fazem parte do cálculo do INCC. Nesse particular, ainda que não haja estatísticas oficiais a respeito dos preços de terrenos urbanos no Brasil, essa lacuna pode ser parcialmente preenchida pela utilização de dados dos valores de locação de imóveis, uma vez que tendem a refletir rapidamente as variações ocorridas no preço da terra (FREW; WILSON, 2002). Assim, como proxy dos preços dos terrenos, o Gráfico 4 mostra a evolução dos valores dos aluguéis em São Paulo entre janeiro de 2008 e dezembro de 2014. 


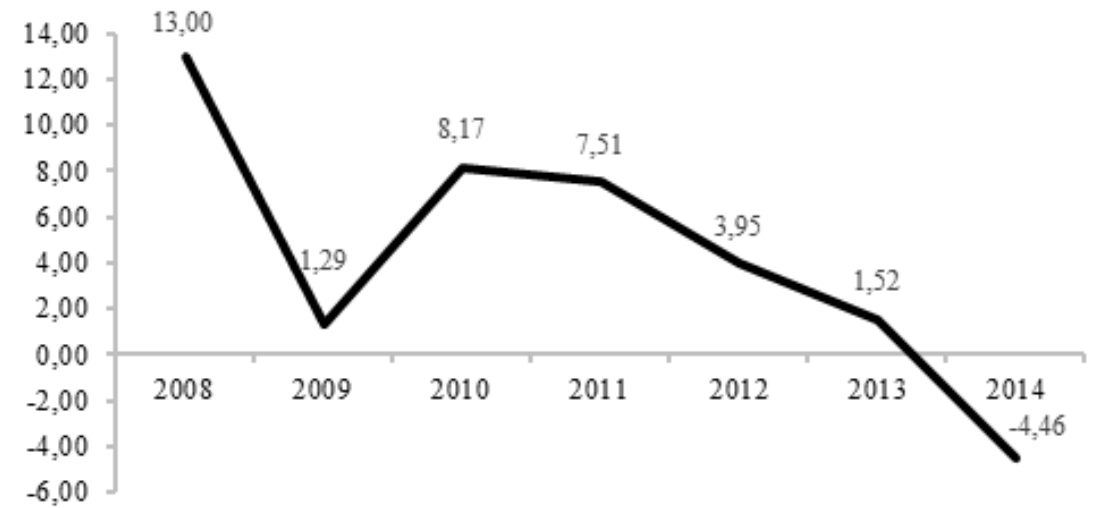

Fonte: Fundação Instituto de Pesquisas Econômicas (2015).

Nota: Série deflacionada pelo IPCA.

Pelo Gráfico 4 observa-se uma variação real média de 4,42\% ao ano no valor de locação e uma variação acumulada no período de 34,2\%. Com efeito, considerando que em alguns casos extremos o preço do terreno chega a 50,0\% do custo do empreendimento, pode-se argumentar que ao menos parte do aumento dos preços dos imóveis é explicado por um processo "ricardiano" de elevação da renda do solo, e não por um movimento especulativo dos agentes econômicos.

No mercado de crédito e, sobretudo, de crédito imobiliário, houve um movimento parecido com o do mercado imobiliário. ${ }^{7} \mathrm{O}$ saldo das operações dessa modalidade de crédito se elevou substancialmente: em dezembro de 2007, representava $\mathrm{R} \$ 48,90$ bilhões, ao passo que, em dezembro de 2014 , chegou a $\mathrm{R} \$$ 338,06 bilhões. Ou seja, uma variação real de 591,31\% em apenas sete anos. Isso fez com que as relações crédito imobiliário/crédito total e crédito imobiliário/PIB,

7 Nos anos 1990, em função do descontrole inflacionário, do alto patamar da taxa de juros e da insegurança jurídica envolvida nesse tipo de operação, o financiamento imobiliário era extremamente escasso e, por conseguinte, as empresas faziam uso de modalidades como o autofinanciamento, tomando recursos para a produção diretamente junto ao consumidor. Além disso, como resultado dessa debilidade, inclusive dos mecanismos públicos de financiamento, a produção de moradias ficou praticamente restrita durante um bom período ao público de média e alta renda (CASTRO, 2001). Apesar dos esforços para se construir instrumentos alternativos no final dos anos 1990, essa realidade somente começaria a mudar a partir do início dos anos 2000 com as mudanças econômicas e institucionais supracitadas e a alteração no foco de aplicação dos recursos do FGTS, voltando-o mais para a sua destinação original, a saber, as famílias de baixa renda. No entanto, cabe destacar que, não obstante todos os avanços nos últimos anos, tanto no setor imobiliário em si, quanto na disponibilidade de recursos para o financiamento dessa atividade, ainda se preservam algumas características de um mercado tipicamente "subdesenvolvido", tais como a dependência de recursos direcionados ou de poupança compulsória e o altíssimo déficit habitacional ainda existente no país. 
que se situavam, respectivamente, em 5,15\% e 1,84\%, em 2007, crescessem para $16,63 \%$ e 9,79\% em 2014, como mostra a Tabela $1 .{ }^{8}$

Tabela 1 - Evolução do crédito total e do crédito imobiliário no Brasil no período 2007-2014

\begin{tabular}{lccccc}
\hline & $\begin{array}{c}\text { Crédito total } \\
\text { (em R\$ milhões) }\end{array}$ & $\begin{array}{c}\text { Crédito } \\
\text { imobiliário } \\
\text { (em R\$ } \\
\text { milhões) }\end{array}$ & $\begin{array}{c}\text { Crédito } \\
\text { imobiliário/ } \\
\text { crédito } \\
\text { total (\%) }\end{array}$ & $\begin{array}{c}\text { Crédito } \\
\text { total/ } \\
\text { PIB (\%) }\end{array}$ & $\begin{array}{c}\text { Crédito } \\
\text { imobili- } \\
\text { ário/ PIB } \\
\text { (\%) }\end{array}$ \\
\hline 2007 & 943.922 & 48.902 & 5,15 & 35,47 & 1,84 \\
2008 & 1.165 .238 & 64.997 & 5,58 & 40,7 & 2,27 \\
2009 & 1.285 .999 & 89.964 & 6,99 & 43,85 & 3,07 \\
2010 & 1.463 .978 & 131.419 & 8,98 & 45,43 & 4,08 \\
2011 & 1.632 .387 & 177.843 & 10,89 & 49,09 & 5,35 \\
2012 & 1.795 .964 & 226.218 & 12,59 & 53,92 & 6,78 \\
2013 & 1.944 .133 & 282.982 & 14,55 & 56,05 & 8,16 \\
2014 & 2.033 .220 & 338.066 & 16,63 & 58,86 & 9,79 \\
\hline
\end{tabular}

Fonte: Banco Central do Brasil (2015).

Nota: Valores de deflacionados pelo IPCA.

Concomitantemente a essa mudança quantitativa, as condições do financiamento imobiliário também melhoraram significativamente ao longo do período. Apesar dos dados disponíveis não permitirem uma análise rigorosa, uma vez que as séries históricas iniciam apenas em março de 2011, nota-se, conforme mostra o Gráfico 5, uma tendência de queda da taxa média de juros do financiamento imobiliário (de 10,76\%, em março de 2011, para 8,9\% em dezembro de 2014) e uma ampliação do prazo médio das concessões (de 248,1 meses, em março de 2011, para 330,8 meses em dezembro de 2014). Além disso, como os preços dos imóveis cresceram mais do que a renda da população (o rendimento médio habitualmente recebido, deflacionado pelo IPCA, apresentou uma variação de $36,94 \%$ entre janeiro de 2004 e novembro de 2014), é razoável supor que uma das condições que permitiu que a demanda continuasse aquecida no mercado imobiliário foi justamente a melhora das condições de financiamento.

$8 \quad$ É verdade que essas relações permanecem baixas se comparadas com os países desenvolvidos e com a maioria dos países em desenvolvimento. No Chile, por exemplo, a relação crédito imobiliário/crédito total era de 25,48\%, em dezembro de 2014, e a relação crédito imobiliário/PIB era de 19,71\% em dezembro de 2013, de acordo com cálculo realizado com base nos dados do Banco Central do Chile [2015]. 
Gráfico 5 - Evolução da taxa média de juros do financiamento imobiliário (\%) e do prazo médio das concessões (meses) no período de março de 2011 a dezembro de 2014

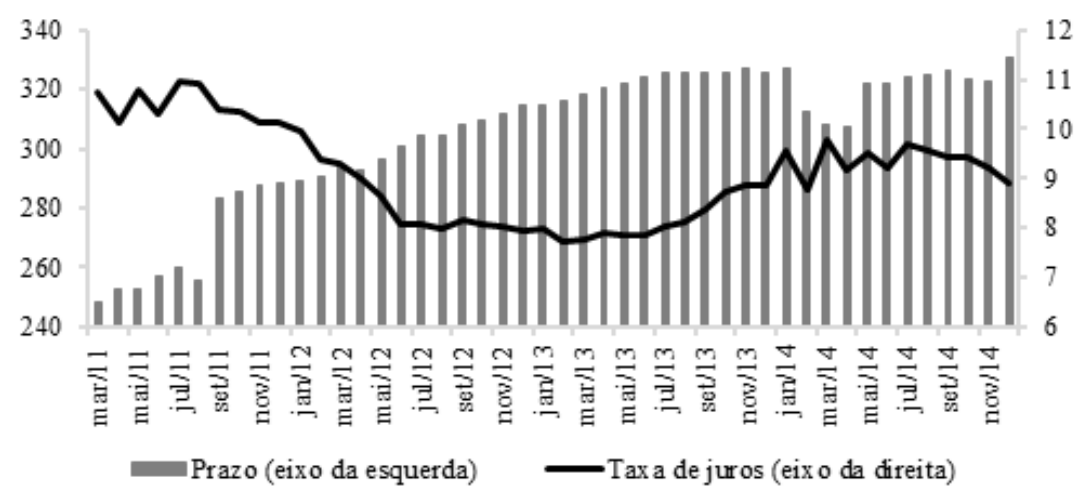

Fonte: Banco Central do Brasil (2015).

Ao mesmo tempo, houve uma clara fragilização da postura financeira das famílias ao longo do período. O endividamento em relação à renda acumulada nos últimos 12 meses (ver Gráfico 6) passou de 18,39\%, em janeiro de 2005, para $45,8 \%$, em novembro de 2014 , com o endividamento imobiliário saindo de $3,1 \%$, no início do período, para $17,74 \%$ ao final do período (um crescimento de $472,26 \%$ contra 83,5\% das demais modalidades). É importante assinalar que, a partir de 2009, há uma aceleração do endividamento imobiliário e um arrefecimento do endividamento das demais modalidades (este passa a cair efetivamente a partir de setembro de 2012), de modo que, desde então, o crescimento do endividamento das famílias pode ser explicado em grande medida por sua parcela habitacional. Ademais, o comprometimento da renda das famílias com o serviço da dívida parcela da renda destinada ao pagamento dos juros e da amortização da dívida apresentou um aumento de $36,09 \%$, passando de $15,6 \%$, em janeiro de 2005 , para 21,23\% em novembro de 2014 (ver Gráfico 7). 
Gráfico 6 - Endividamento das famílias em relação à renda acumulada dos últimos 12 meses (\%), no período de janeiro de 2005 a novembro de 2014

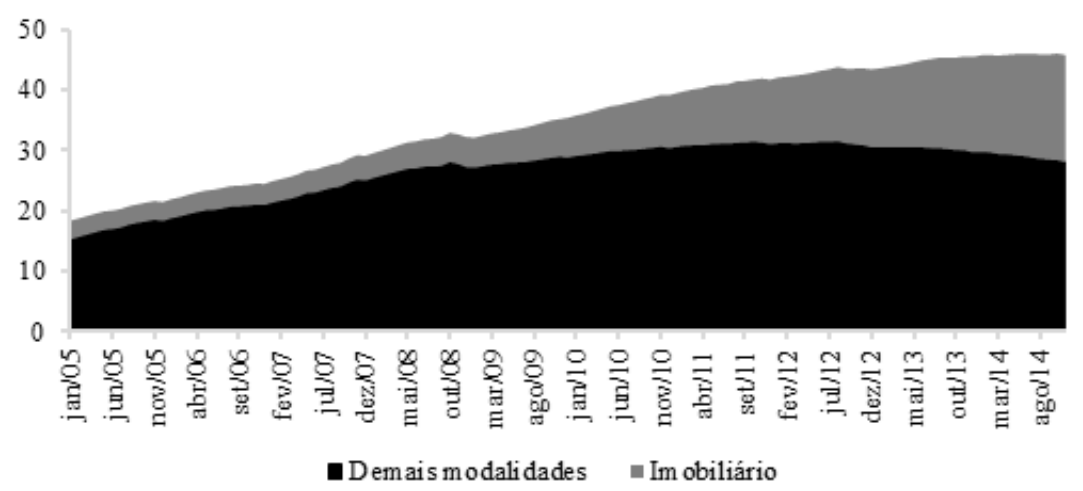

Fonte: Banco Central do Brasil (2015).

Gráfico 7 - Comprometimento da renda das famílias com o serviço da dívida (\%) no período de janeiro de 2005 a novembro de 2014

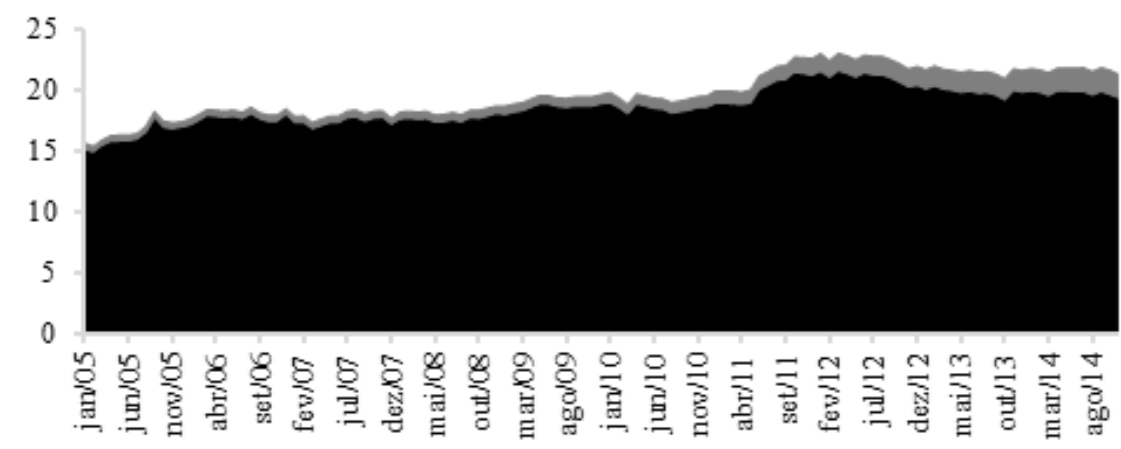

- Demais modalidades Imobiliário

Fonte: Banco Central do Brasil (2015).

Duas considerações são necessárias para se compreender esse fenômeno. Primeiramente, embora tenha crescido muito nos últimos anos, o nível de endividamento das famílias brasileiras está próximo ao de outros países emergentes e abaixo dos países desenvolvidos, ao passo que o comprometimento da renda das famílias com o serviço da dívida está em um nível elevado, mesmo para países desenvolvidos - nos Estados Unidos e em Portugal, por exemplo, essa parcela corresponde a 9,9\% e 3,2\% da renda, respectivamente (INTERNATIONAL MONETARY FUND, [2015]). Esse aparente paradoxo se explica pelo pior perfil do endi- 
vidamento das famílias brasileiras vis-à-vis o de outros países em virtude do prazo relativamente curto desses empréstimos e, sobretudo, das elevadas taxas de juros cobradas. Segundo, o endividamento associado ao crédito imobiliário não foi o responsável pelo aumento do comprometimento da renda das famílias e, portanto, pela fragilização da sua posição financeira, pois, conforme observado no Gráfico 7, em média somente cerca de $1 \%$ da renda foi comprometida com o pagamento de juros e amortização da dívida imobiliária entre 2005 e 2014, principalmente porque os juros da casa própria são baixos e os prazos de pagamento são consideravelmente longos. ${ }^{9}$

Por fim, é importante ressaltar que os movimentos descritos ocorreram em um contexto de relativa prosperidade econômica e de expectativas positivas em relação às rendas futuras. O Gráfico 8 mostra que o PIB vinha crescendo a uma média de $2,5 \%$ ao ano até 2004 , quando, a partir de então, passou a crescer com uma média anual de $3,75 \%$, bem como as expectativas da população em relação à situação geral do país, medidas pelo índice de confiança do consumidor da Fecomércio-SP, ${ }^{10}$ atingiram o nível mais alto da série histórica, passando de 90,4 pontos, em 1999, para 161,77 em 2012.

Gráfico 8 - Taxa de crescimento do PIB (\%) e média do índice de confiança do consumidor da Fecomércio-SP (pontos), no período 1994-2014

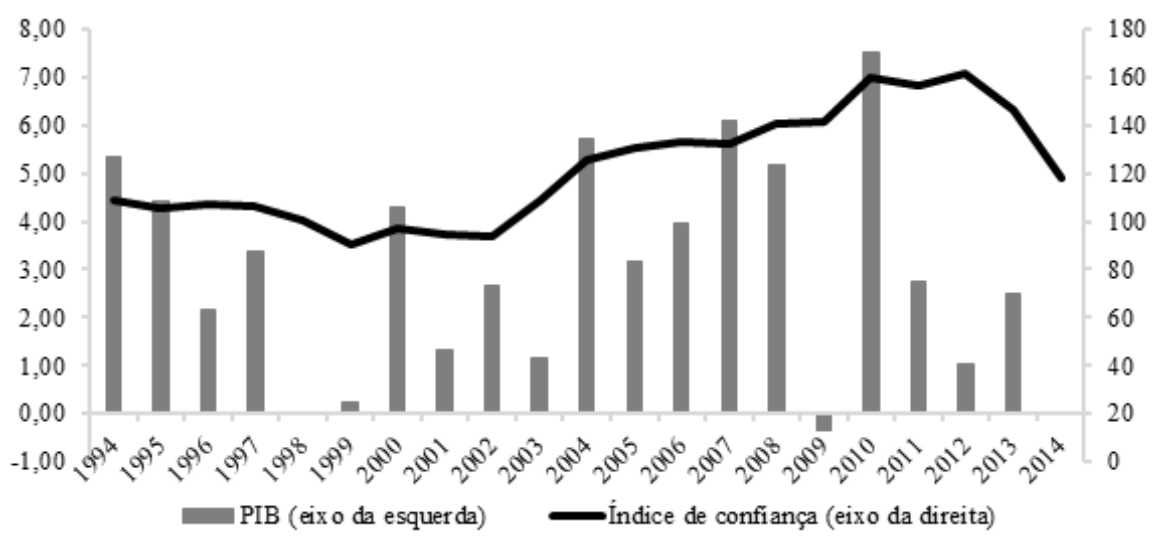

Fonte: Banco Central do Brasil (2015) e Fecomércio-SP (2015).

Em síntese, pode-se especular que o contexto de crescimento econômico e expectativas eufóricas em relação ao futuro da economia brasileira, acompanhado

9 Para uma explicação mais detalhada a respeito do nível e perfil do endividamento das famílias brasileiras no período recente, ver Paim (2015).

10 Esse índice vai de 0 a 200 pontos, sendo que 0 indica pessimismo total e 200 representa otimismo total. O referido índice foi utilizado como uma proxy para o "estado de confiança", pois, conforme visto na seção teórica, essa variável é um dos fatores principais para o ciclo econômico. 
de importantes mudanças estruturais nos setores imobiliário e de crédito, contribuíram para aumentos substanciais dos preços dos imóveis entre 2004 e 2014, concentrado principalmente em algumas capitais do Brasil. Esses aumentos superaram em larga medida a elevação dos custos do setor e da renda da população ao longo do período analisado. Paralelamente, houve um crescimento expressivo do crédito imobiliário no país e uma melhora das condições de financiamento, assim como uma elevação da relação dívida/receita e, consequentemente, uma fragilização da posição financeira das famílias.

\subsection{Análise Econométrica}

O approach teórico pós-keynesiano mostra que o preço fundamental de um ativo depende de convenções sociais e de equilíbrios momentâneos entre posições bear e bull, todas fundadas em perspectivas imperfeitas e heterogêneas. Além disso, as perspectivas quanto aos eventos futuros de longo prazo que definem o preço "fundamental" de um ativo são altamente incertas. Entretanto, Keynes afirma que "[...] we should not conclude that everything depends on waves of irrational psychology. On the contrary, the state of long-term expectation is often steady" (KEYNES, 2007 apud HAYES, 2013, p. 2). ${ }^{11}$ Em outras palavras, a valoração de um ativo por meio de convenções sociais pode apresentar certa estabilidade ao longo do tempo e variar de acordo com a evolução de algumas variáveis fundamentais.

Pois bem, a presente subseção busca avaliar, à luz da teoria pós-keynesiana, a existência de correlação de determinadas variáveis fundamentais, apontadas pela literatura de análise de preços imobiliários, com a evolução dos preços no Brasil.

O principal problema que surge ao tentarmos analisar econometricamente os fundamentos subjacentes à evolução dos preços no mercado imobiliário brasileiro é a baixa disponibilidade de dados. Alguns dados, tais como juros cobrados em empréstimos imobiliários e valores dos aluguéis, são disponíveis em períodos muito curtos ou somente para poucas cidades. Essas limitações dificultam a elaboração de modelos econométricos mais consistentes para se analisar a dinâmica do mercado imobiliário.

Todavia, a despeito dessa limitação, realizou-se um teste econométrico incorporando as técnicas e as variáveis fundamentais avaliados por diversos trabalhos da área (KALRA MIHALJEK; DUENWALD, 2000; CHUNG; KIM, 2004; CADIL, 2009; AHUJA; PORTER, 2010). ${ }^{12}$

11 KEYNES, J. M. The general theory of employment, interest and money. London: Palgrave Macmillan, 2007.

12 É importante ressaltar que foi aventada a possibilidade de se desenvolver um vector error correction model (VECM), visando realizar uma análise mais estrutural para se verificar a existência da bolha imobiliária. Todavia, como tais modelos requerem dados de maneira intensiva, logo, devido à baixa disponibilidade de dados, não foi possível realizar a análise desejada. Além disso, 
As variáveis selecionadas encontram-se na Tabela 2. Os dados foram coletados em frequência trimestral e transformados em diferença logarítmica T/T. Em seguida, as variáveis foram testadas por meio do teste de Dickey-Fuler aumentado para se verificar o grau de integração. Tendo em vista que a variável dependente, qual seja, o índice de valores garantidos (IVG), tem raiz unitária, verificou-se por meio do teste de Johansen se essa era cointegrada com as demais. Como a variável "saldo do crédito total imobiliário" não cointegra com a variável dependente, não foi utilizada na regressão, sob o risco de gerar uma regressão espúria.

Tabela 2 - Variáveis testadas

\begin{tabular}{|c|c|c|c|}
\hline Variável & Código & $\begin{array}{l}\text { Grau de } \\
\text { integração }\end{array}$ & $\begin{array}{l}\text { Cointegração } \\
\text { com a } \\
\text { variável } \\
\text { dependente }\end{array}$ \\
\hline $\begin{array}{l}\text { Índice de valores de garantia de imó- } \\
\text { veis Residenciais financiados reais } \\
\text { (BCB) }\end{array}$ & vt_ivg & $\mathrm{I}(1)$ & - \\
\hline Salário médio real (IBGE) & vt_sal & $\mathrm{I}(0)$ & - \\
\hline $\begin{array}{l}\text { Índice de Atividade Econômica do } \\
\text { Banco Central (BCB) }\end{array}$ & vt_ibc & $\mathrm{I}(0)$ & - \\
\hline $\begin{array}{l}\text { População economicamente ativa } \\
\text { (IBGE) }\end{array}$ & vt_pea & $\mathrm{I}(0)$ & - \\
\hline $\begin{array}{l}\text { Confiança do consumidor (Fecomér- } \\
\text { cio-SP) }\end{array}$ & vt_conf & $\mathrm{I}(0)$ & - \\
\hline $\begin{array}{l}\text { Endividamento total das famílias em } \\
\text { relação à renda acumulada (BCB) }\end{array}$ & $\begin{array}{l}\text { vt_en- } \\
\text { div }\end{array}$ & $\mathrm{I}(1)$ & Sim \\
\hline $\begin{array}{l}\text { Índice nacional de custos da } \\
\text { construção (FGV) }\end{array}$ & vt_incc & $\mathrm{I}(1)$ & Sim \\
\hline Saldo de crédito imobiliário (BCB) & vt_cr & $\mathrm{I}(1)$ & Não \\
\hline
\end{tabular}

Fonte: Banco Central do Brasil (2015).

Nota: Séries extraídas do sistema gerenciador de séries temporais do BCB.

Dadas as variáveis a serem testadas, procedeu-se à regressão por mínimos quadrados ordinários. Testaram-se as variáveis com até quatro defasagens, usando-se os critérios de seleção de Akaike e Schwarz para se definir a melhor configuração. Seguindo o método utilizado por alguns autores (CHUNG; KIM, 2004;

mesmo que os dados se ajustassem bem a um modelo de equações múltiplas, correr-se-ia o risco de incorrer no problema de overfitting, ou seja, problema que surge quando a quantidade de regressores é tão grande frente ao número de observações que se torna difícil separar sinal de ruído. Diante dessas limitações, optou-se por verificar possíveis correlações entre as variáveis, utilizando-se como referência modelos desenvolvidos pelos autores citados. 
CADIL, 2009) para verificar a existência de bolhas no mercado imobiliário, adicionou-se a variável dependente com defasagens na regressão de modo a avaliar se a evolução dos preços passados está correlacionada com a variação do preço presente.

A regressão encontrada apresentou os seguintes resultados (ver Tabela 3) e representação (ver Gráfico 9):13

Tabela 3 - Resultado da regressão

\begin{tabular}{l|l|l|l|l}
\hline Variável & Coeficiente & $\begin{array}{l}\text { Erro } \\
\text { padrão }\end{array}$ & $\begin{array}{l}\text { Estatística } \\
\boldsymbol{t}\end{array}$ & $\boldsymbol{p}$-valor \\
\hline C & $-0,004579$ & 0,004002 & $-1,144126$ & 0,2611 \\
VT_INCC(-1) & 0,309582 & 0,113649 & 2,724011 & 0,0104 \\
VT_IVG(-3) & 0,726017 & 0,120374 & 6,031340 & 0,0000 \\
VT_ENDIV_TOTAL(-2) & 0,250757 & 0,125347 & 2,000498 & 0,0540 \\
VT_CONF_CONS & 0,058756 & 0,031935 & 1,839826 & 0,0751 \\
R^2 & 0,732471 & P-valor estatística F & 0,000000 \\
\hline
\end{tabular}

Fonte: Elaboração própria utilizando o software Eviews.

Nota: Variável dependente: VT_IVG; Amostra: 2005-T4 a 2014-T4; número de observações: 37; e covariância ajustada por Newey-West.

Gráfico 9 - Variação efetiva, modelada e resíduos

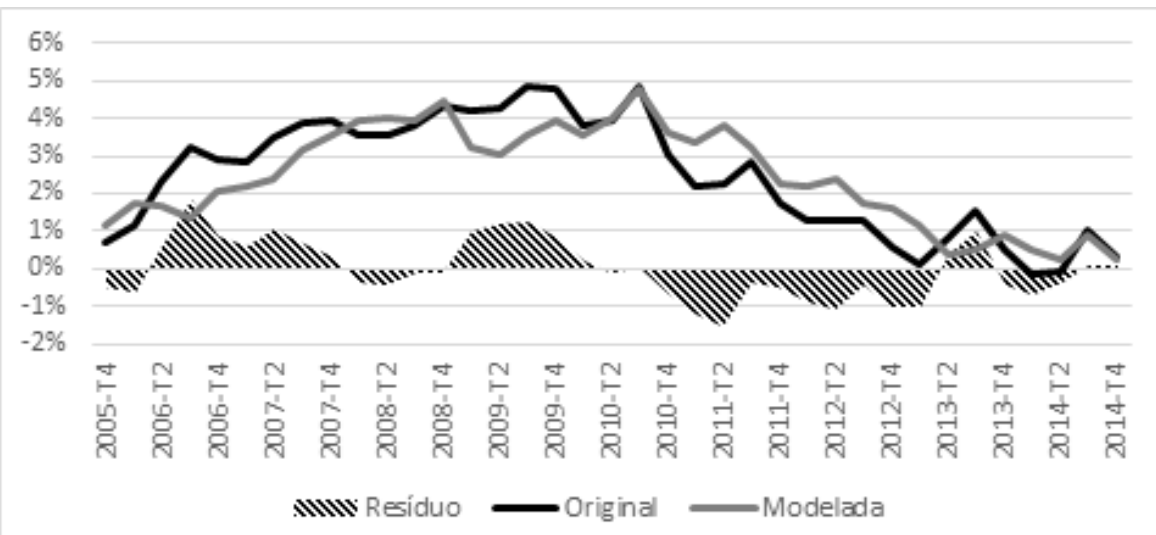

Fonte: Elaboração própria a partir do software Eviews.

13 As variáveis salário real, população economicamente ativa e Índice de Atividade Econômica do Banco Central não foram significantes e sua inclusão ou exclusão não alterou significativamente os coeficientes das demais variáveis, de modo que não foram utilizadas. 
A partir da regressão estimada, avaliou-se a presença de raiz unitária nos resíduos, tendo em vista que foram utilizadas variáveis cointegradas. Para um nível de significância de 10\%, rejeitou-se a hipótese nula de que havia uma raiz unitária na série. Ademais, seguindo o método adotado por Cadil (2009), procurou-se avaliar a contribuição de cada uma das variáveis independentes para a evolução do preço dos imóveis no Brasil. O método consistiu em calcular a seguinte fórmula para cada uma das variáveis:

$$
P_{i}=\frac{\sum_{t=1}^{T} b_{i} X_{i, t}}{\sum_{t=1}^{T} Y_{\text {est }, t}}
$$

em que $P_{i}$ é a participação da variável i na variação dos preços estimada pelo modelo; $b_{i}$ é o coeficiente da regressão; $X_{i, t}$ é a variável $i$; e $Y_{\text {est }}$ é a variação no preço estimada pelo modelo.

$O$ resultado encontrado foi o seguinte:

Tabela 4 - Participação variáveis explicativas na variação total do modelo

\begin{tabular}{cc}
\hline Variável & $\boldsymbol{P}_{\boldsymbol{i}}$ \\
\hline vt_ivg(-3) & $52,3 \%$ \\
vt_incc(-1) & $22,5 \%$ \\
vt_endiv(-2) & $20,3 \%$ \\
vt_conf & $4,9 \%$ \\
\hline
\end{tabular}

Fonte: Elaboração própria.

Em suma, o modelo elaborado para avaliar possíveis fatores fundamentais por trás da evolução dos preços de imóveis no Brasil encontrou uma forte participação da variação nos preços de períodos anteriores: aproximadamente, metade da variação prevista pelo modelo adveio das mudanças nos preços, o que pode ser um indicador de bolha no mercado imobiliário. Entretanto, tal conclusão deve ser apreciada com ressalvas devido às limitações na disponibilidade de dados, ao modelo não estrutural apresentado e à proxy utilizada para avaliar a expectativa de evolução dos preços futuros. Adicionalmente, quatro considerações merecem ser destacadas: a) variáveis fundamentais que não estavam disponíveis para análise podem explicar parte da correlação com os preços; b) o segundo fator mais importante no modelo foi a variação trimestral nos custos de construção, os quais explicaram 22,5\% da variação nos preços; c) a variação no endividamento das famílias, explicado em grande parte pelo aumento do endividamento imobiliário, foi responsável por 20,3\% das elevações; e d) a variação na confiança do consumidor foi responsável por $5 \%$ da variação nos preços do modelo. 


\section{Considerações Finais}

Este artigo visou avaliar a existência de uma bolha imobiliária no Brasil. Nesse sentido, inicialmente apresentou-se uma discussão de cunho teórico, tendo como referência a teoria pós-keynesiana. A partir da noção de incerteza e da teoria de precificação de ativos elaborada por Keynes, respectivamente, nos capítulos 12 e 17 da GT, e pelos autores pós-keynesianos, definiu-se bolha de ativos como uma situação em que o comportamento irracional dos agentes leva a um aumento dos preços dos ativos, independentemente dos fundamentos econômicos, ou, alternativamente, ocorre um crescimento contínuo da relação entre os preços dos ativos (reais ou financeiros) e os custos de produção. Ademais, consoante à HFF de Minsky, foi argumentado que os momentos de prosperidade econômica, com expectativas eufóricas em relação ao futuro, tendem a levar a uma fase de progressiva expansão dos empréstimos bancários, inflação de ativos e deterioração da posição financeira dos agentes econômicos. Quando esse processo se reverte, o movimento oposto se materializa, levando à crise.

Com base no referido approach teórico, analisou-se a bolha de ativos no mercado imobiliário brasileiro. As evidências empíricas apresentadas levam, por um lado, a se concluir que os custos de produção e outras variáveis fundamentais não são suficientes para explicar a variação significativa dos preços dos imóveis no Brasil. Nesse particular, a intuição é que a variação real de 159,75\%, entre 2004 e 2014, dos preços dos imóveis, apresentou um componente inerentemente especulativo, típico de dinâmicas de economias monetárias. Por outro lado, o mercado de crédito, o endividamento das famílias e as condições gerais da economia contribuíram para que houvesse um comportamento típico de bolha imobiliária, contribuindo, assim, para justificar a expressiva variação real dos preços dos imóveis. Todavia, essas conclusões devem ser observadas com cautela, na medida em que não se conseguiu contornar o problema da insuficiência de dados sobre o setor, em especial no que diz respeito aos preços dos terrenos.

Diante do cenário de indícios de uma bolha imobiliária, duas questões parecem relevantes: primeiramente, haverá uma correção drástica dos preços no mercado imobiliário, ou apenas uma acomodação? Segundo, caso haja essa correção mais acentuada, quais serão as consequências para a economia brasileira? Ou, em outras palavras, ocorrerá no Brasil algo similar ao que aconteceu nos países que vivenciaram uma bolha imobiliária no período recente, como Estados Unidos e Espanha?

Em relação à primeira pergunta, é difícil saber. $\mathrm{O}$ que as experiências históricas mostram é que nem todo episódio de inflação de ativos foi seguido por uma 
correção de grande monta. ${ }^{14}$ No caso brasileiro, é possível observar um aumento dos preços dos imóveis inferior à inflação e, em certos casos, até mesmo uma queda nominal desses preços. ${ }^{15}$ Ademais, cabe ressaltar que a queda parece ser mais pronunciada do que aquela observada nos indicadores oficiais de preços do mercado imobiliário, uma vez que se tornou prática usual no mercado a concessão de amplos descontos no momento da negociação, especialmente dos imóveis em estoque.

A segunda questão permite maiores especulações. Certamente, uma diminuição dos preços dos imóveis resultará em uma redução do número de lançamentos e do montante investido nesse mercado. Como consequência, uma vez que o setor imobiliário é um grande gerador de empregos e impulsiona uma ampla cadeia produtiva (que vai desde a extração mineral até a comercialização de imóveis), a desaceleração do investimento imobiliário deve representar um impacto não desprezível na atividade econômica e no emprego.

Porém, ao contrário do que ocorreu em outros países, se configurando o "estouro" da bolha imobiliária, não se espera para o caso brasileiro uma crise financeira como um desdobramento provável. ${ }^{16}$ Razões não faltam para isso, quais sejam: a securitização dos contratos de financiamento imobiliário começou a ser desenvolvida apenas no final dos anos 1990, com a instituição do Sistema de Financiamento Imobiliário (SFI); o financiamento imobiliário depende essencialmente de recursos direcionados da caderneta de poupança e do FGTS, cujos montantes, em grande parte, são provenientes de bancos públicos (a Caixa Econômica Federal detém aproximadamente 70\% desse mercado); não há, no Brasil,

14 Ver, por exemplo, IMF (2003).

15 O IVG-R apresentou uma variação acumulada de 1,24\% de janeiro a julho de 2015.

16 A relação mais ilustrativa entre crise financeira e queda dos preços no mercado imobiliário é que ocorreu, recentemente, na economia norte-americana. Nesse particular, não é demais ressaltar, brevemente, as origens e os desdobramentos da crise do subprime. Nos Estados Unidos, devido à desregulamentação financeira e, por conseguinte, à proliferação do shadow banking, o sistema financeiro passou a assumir maiores riscos com o financiamento de hipotecas do mercado subprime. Para mitigar os riscos de tais operações, as instituições financeiras transformavam essas dívidas em títulos (securities) que eram vendidos e negociados para os bancos de investimento, que, por sua vez, vendiam, principalmente no mercado secundário, para diferentes tipos de investidores (famílias, investidores institucionais, etc.). A securitização de recebíveis, através de asset backed securities e collaterized debt obligations, classificados como AAA pelas agências da rating, permitia às instituições financeiras ofertarem mais crédito, formando-se, assim, uma bolha especulativa, que estourou com a mudança das taxas de juros e, consequentemente, levou à inadimplência dos mutuários. Assim, em um contexto de queda do valor dos imóveis e aumento da incerteza, os detentores de títulos de dívidas imobiliárias tentaram vender suas posições; todavia, não encontrando compradores, os preços dos referidos títulos despencaram, contagiando, assim, outros ativos financeiros (ações, títulos públicos, etc.). Como contrapartida, as taxas de juros cobradas pelos empréstimos interbancários passaram a se elevar consideravelmente, cuja consequência foi a redução da oferta de crédito. Portanto, a crise financeira se originou como uma crise de crédito, devido a uma inadimplência maior do que a esperada no segmento subprime, e acabou gerando uma crise de liquidez, resultante do fato de todos os detentores de quaisquer ativos financeiros tentaram se livrar deles ao mesmo tempo. Enfim, para uma análise sobre a crise do subprime, ver, por exemplo, Borça Júnior e Torres Filho (2008). 
contratos de financiamento imobiliário similares aos que estavam sendo praticados nos Estados Unidos no período pré-crise do subprime, nos quais não se exigiam qualquer comprovação de rendimento ou se iniciava a amortização do principal da dívida apenas no final do período; ${ }^{17} \mathrm{e}$, finalmente, o sistema financeiro brasileiro é altamente capitalizado, tornando-o, desse modo, mais resiliente a mudanças nas condições econômicas. ${ }^{18}$

\section{Referências}

AHUJA, A.; PORTER, N. Are house prices rising too fast in Hong Kong SAR? Washington, DC: International Monetary Fund, 2010. (IMF Working Paper, n. 273).

BANCO CENTRAL DE CHILE. Base de datos estadísticos. Santiago de Chile, 2015. Disponível em: <http://si3.bcentral.cl/Siete/secure/cuadros/home.aspx> . Acesso em: 1 fev. 2015.

BANCO CENTRAL DO BRASIL. Relatório de Estabilidade Financeira, Brasília, DF, v. 13, n. 1, p. 1-69, mar. 2014.

. Séries Temporais. Brasília, DF, 2015. Disponível em: <http://www.bcb.gov. br/?serietemp >. Acesso em: 1 fev. 2015.

BANK FOR INTERNATIONAL SETTLEMENTS. 84th Annual Report 2014. Basel, Switzerland, 2014. Disponível em: <http://www.bis.org/publ/arpdf/ar2014e.htm>. Acesso em: 15 jan. 2015.

BEZERRA, M. M. O. et al. Formação, sustentação ou implosão de uma bolha imobiliária? A dinâmica de preços no mercado de imóveis de Natal no período 2005-2010. Economia e Sociedade, v. 22, n 1, p. 167-196, abr. 2013.

BORÇA JÚNIOR, G. R.; TORRES FILHO, E. T. Analisando a crise do subprime. Revista do BNDES, v. 15, n. 30, p. 129-159, dez. 2008.

CADIL, J. Housing price bubble analysis: the case of the Czech Republic. Prague Economic Papers, v. 18, n. 1, p. 39-49, 2009.

CÂMARA BRASILEIRA DA INDÚSTRIA DA CONSTRUÇÃO. Banco de dados, 2015. Disponível em: <http://www.cbicdados.com.br/home>. Acesso em: 1 fev. 2015.

CARDOSO, A. L.; LEAL, J. A. Housing markets in Brazil: recent trends and governmental responses to the 2008 crisis. International Journal of Housing Policy, v. 10, n. 2, p. 191-208, June 2010.

17 O mercado de subprime era o segmento de tomadores de empréstimos normalmente considerados de alto risco, seja pela instabilidade da renda e do emprego dos tomadores, seja por outros fatores.

18 Um teste de estresse realizado no Relatório de Estabilidade Financeira do BCB, publicado em março de 2014, mostra que para o desenquadramento de alguma instituição financeira seria necessária uma queda dos preços dos imóveis da ordem de $45 \%$, maior do que a verificada durante os três primeiros anos da crise do subprime. 
CARVALHO, E. R. A. Bolhas especulativas e preços de imóveis na cidade de São Paulo. Revista do Parlamento Paulistano, v. 2, n. 2, p. 66-80, jan./jun. 2012.

CASTRO, C. M. P. A explosão do autofinanciamento na produção de moradia em São Paulo nos anos 1990 e as cooperativas habitacionais. In: Encontro Nacional da ANPUR, XI, 2001, Rio de Janeiro. Anais... São Paulo: UFSCar, 2001.

CHUNG, H. S.; KIM, J. H. Housing speculation and housing price bubble in Korea. South Korea: School of Public Policy and Management, 2004. (Working Paper Series, n. 04-06).

D’AGOSTINI, L. L. M. A bolha imobiliária no Brasil está formada. Economia $\mathcal{E}$ Tecnologia, v. 6, n. 4, p. 41-51, out./dez. 2010.

DAVIDSON, P. Post Keynesian Macroeconomic Theory. Aldershot: Edward Elgar, 1994.

DYMSKI, G. Bolha de ativos e crises em Minsky: uma abordagem especializada. In: FERRARI FILHO, F.; PAULA, L. F. R. Globalização financeira: ensaios de macroeconomia aberta. Petrópolis: Vozes, 2004. p. 402-448.

FEDERAÇÃO DO COMÉRCIO DO ESTADO DE SÃO PAULO. Indicadores econômicos. São Paulo, 2015. Disponível em: <http://www.fecomercio.com.br/Estudos/icc>. Acesso em: 22 fev. 2015.

FERRARI FILHO, F.; CONCEIÇÃO, O. A. C. The concept of uncertainty in Post Keynesian theory and Institutional economics. Journal of Economic Issues, v. 39, n. 3, p. 579-594, Sept. 2005.

FREW, J.; WILSON, B. Estimating the connection between location and property value. Journal of Real Estate Practice and Education, v. 5, n. 1, p. 17-25, 2002.

FUNDAÇÃO GETÚLIO VARGAS. Indicadores de preços. 2015. Disponível em: < http:// portalibre.fgv.br/main.jsp?lumChannelId=40288081 1D8E34B9011D92AF56810C57> . Acesso em: 22 fev. 2015.

FUNDAÇÃO INSTITUTO DE PESQUISAS ECONÔMICAS. Índices, 2015. Disponível em: <http://www.fipe.org.br/web/index.asp>. Acesso em: 1 fev. 2015.

HAYES, M. Efficient markets hypothesis. 2013. Disponível em: < http://people.ds.cam.ac.uk/ mgh37/EMHpreprint.pdf > . Acesso em: 22 fev. 2015.

INSTITUTO BRASILEIRO DE GEOGRAFIA E ESTATÍSTICA. Pesquisa Nacional por Amostra de Domicílio, 2015. Disponível em: < http://www.sidra.ibge.gov.br/pnad/default.asp > . Acesso em: 22 fev. 2015.

INTERNATIONAL MONETARY FUND. Financial soundness indicators (FSIs). [2015]. Disponível em: <http://data.imf.org/?sk=9F855EAE-C765-405E-9C9A-A9DC2C1FEE47>. Acesso em: 1 fev. 2015.

. When bubbles burst. In: World Economic Outlook. Washington, DC: International Monetary Fund, Apr. 2003. p. 61-94. 
KALRA, S.; MIHALJEK, D.; DUENWALD, C. Property prices and speculative bubbles: evidence from Hong Kong SAR. Washington, DC: International Monetary Fund, 2000. (IMF Working Paper, n. 2).

KEYNES, J. M. A treatise on money. New York: AMS Press, 1976.

. The general theory and after: defence and development. London: Macmillan, 1973. (The Collected Writings of John Maynard Keynes, v. 14). 2007. . The general theory of employment, interest and money. London: Palgrave Macmillan,

LIMA JÚNIOR, J. R. Alerta de bolha. São Paulo: Escola Politécnica, Universidade de São Paulo. jul./set. 2011. (Carta do NRE-POLI, n. 25)

. Lições sobre bolhas. São Paulo: Escola Politécnica, Universidade de São Paulo, abr./ jun. 2014. (Carta do NRE-POLI, n. 36).

MARÇAL, E. F.; GALA, P.; MORI, R. Bolha no mercado imobiliário em São Paulo? Evidência baseada em testes econométricos. São Paulo: FGV-EESP, out. 2012. (Carta CEMAP, n. 12).

MENDONÇA, M. J.; SACHSIDA, A. Existe bolha no mercado imobiliário brasileiro? Rio de Janeiro: Ipea, 2012. (Texto para discussão, n. 1762).

MINSKY, H. P. John Maynard Keynes. New York: McGraw Hill, 2008.

O GLOBO. Em recente visita ao Brasil, Robert Shiller alertou para possivel bolha no mercado imobiliário do país. 19 de outubro de 2013. Disponível em: <http://oglobo.globo.com/ economia/em-recente-visita-ao-brasil-robert-shiller-alertou-para-possivel-bolha-nomercado-imobiliario-do-pais-10357107>. Acesso em: 15 jan. 2015.

PAIM, B. O perfil da dívida das famílias e o sistema financeiro nacional. Indicadores Econômicos FEE, Porto Alegre, v. 42, n. 4, p. 9-24, 2015.

ROUBINI, N. Back to Housing Bubbles. 2013. Disponivel em: < http://www.project-syndicate. org/commentary/nouriel-roubini-warns-that-policymmakers-are-powerless-to-rein-in-frothyhousing-markets-around-the-world >. Acesso em: 15 jan. 2015.

Recebido em: 14/04/2015. Aceito em: 03/11/2015. 